\title{
Inquiry in Science Education
}

\author{
Nani Teig
}

Author Note

Nani Teig, Department of Teacher Education and School Research, Faculty of Educational Sciences, University of Oslo.

Correspondence concerning this article should be addressed to Nani Teig, Department of Teacher Education and School Research, Faculty of Educational Sciences, University of Oslo, Postbox 1099 Blindern, 0317 Oslo, Norway. E-Mail: nani.teig@ils.uio.no

Accepted manuscript after peer-review process (green open access).

Teig, N. (2021, in press). Inquiry in science education. In Nilsen, T., Stancel-Piatak, A., \& Gustafsson, J.E. International Handbook of Comparative Large-Scale Studies in Education. New York City: Springer Open. 


\section{Inquiry in Science Education}

\section{A. Author's name and detail}

Nani Teig

Department of Teacher Education and School Research, the University of Oslo, Norway nani.teig@ils.uio.no

\section{B. Abstract}

Inquiry has played a major role in the past and present science education reforms around the world. Despite a great number of studies leveraging TIMSS and PISA data to investigate inquiry in science education, there is little effort to synthesize their findings. The present study aims to systematically review how TIMSS and PISA data were used to investigate inquiry and discuss how the findings contributed to the overall research on inquiry in science education. Patterns and findings from the TIMSS and PISA research were synthesized across the three strands of inquiry research to identify the relevant factors that explain (1) teachers' frequent implementation of inquiry as an instructional approach, (2) students' performance in inquiry or inquiry as an instructional outcome, and (3) the relationships between inquiry as an instructional approach and outcome. Findings indicated that the majority of the studies emphasized the third strand of inquiry research by examining the relationships between inquiry and student achievement. Although these studies used similar data, their conceptualizations and measurements of inquiry as an instructional approach varied considerably. This review provides an overview of the assessment of inquiry in TIMSS and PISA targeted to science education researchers who are unfamiliar with this field in the hope of encouraging them to utilize these data. It also encourages other researchers to reflect upon the knowledge gained from harnessing TIMSS and PISA data as well as the challenges and opportunities that lie ahead.

\section{Keywords}

Inquiry-based teaching, PISA, science education, scientific inquiry, TIMSS.

\section{Introduction}

The number of studies utilizing international large-scale assessments (ILSAs) — such as the Programme for International Student Assessment (PISA) and Trends in International Mathematics and Science Study (TIMSS) - to inform research in science education has been on the rise in the past two decades (Hopfenbeck et al., 2018; Liou \& Hung, 2015). In a systematic review of studies focusing on PISA, science was found to be the third most frequently studied discipline, after education and economics (Hopfenbeck et al., 2018). A considerable number of these studies focused on examining inquiry in science education (e.g., Jiang \& Mccomas, 2015). This finding is unsurprising because inquiry has been viewed as a central aspect in improving science teaching and learning (Abd-El-Khalick et al., 2004; Crawford, 2014). Inquiry has also played a prominent role in science education reforms worldwide (Abd-El-Khalick et al., 2004; Crawford, 2014; Furtak \& Penuel, 2019). 
Using ILSA studies, researchers could investigate a broad range of research questions that may contribute to better enactment of inquiry-based science teaching and the development of students' scientific inquiry skills. For instance, some researchers have focused on different types of inquiry activities that influence student achievement and motivation in science (e.g., Aditomo \& Klieme, 2020; Jerrim, Oliver, \& Sims, 2019), the importance of teacher beliefs in fostering inquiry teaching (e.g., Pongsophon \& Herman, 2017; Teig, Scherer, \& Nilsen, 2019), and students' mastery of scientific inquiry skills (e.g., Kabiri, Ghazi-Tabatabaei, Bazargan, Shokoohi-Yekta, \& Kharrazi, 2017; Yip, Chiu, \& Ho, 2004). While a great deal of studies has investigated inquiry using TIMSS and PISA data, there has been little effort to review and synthesize these findings for facilitating further research. Although previous studies have reviewed a number of publications on ILSAs (e.g., Hopfenbeck et al., 2018), none of these studies focused on science research even though this field has frequently been investigated. Hence, the question remains of the extent to which researchers have taken advantage of TIMSS and PISA data to advance research in science education, specifically in investigating inquiry. Consequently, the present study aims to systematically review literature on secondary analysis of TIMSS and PISA data in order to synthesize how these data were used to investigate inquiry and contributed to research on inquiry. This study may serve as an overview of TIMSS and PISA for science education researchers who are unfamiliar with these assessments. It may also encourage others to reflect on the knowledge gained from utilizing ILSA data and the research gaps that can be bridged using these data in the field of science education.

\section{E. Main Text}

\section{Theoretical Framework}

\section{Inquiry as an instructional approach and outcome}

A large number of studies have demonstrated the effectiveness of engaging students with inquiry as a basis for quality teaching (e.g., Estrella, Au, Jaeggi, \& Collins, 2018; Furtak, Seidel, Iverson, \& Briggs, 2012). But what is inquiry? Despite a wide agreement regarding the importance of inquiry for student learning, debate remains on how to conceptualize inquiry and what it means to teach science as inquiry (Crawford, 2014). The present study refers to the National Science Education Standards (National Research Council [NRC], 1996) that conceptualizes inquiry in two ways. First, inquiry refers to teaching methods and strategies intended to help students enhance their understanding of science content. The second interpretation of the standards refers to inquiry as the process skills and abilities students should understand and be able to perform. The first aspect denotes inquiry as an instructional approach in that inquiry is a means and the understanding of science content is the end. Conversely, the second aspect represents inquiry as an instructional outcome in which the subject matter serves as a means to facilitate the development of scientific inquiry skills as the ends (Abd-El-Khalick et al., 2004). Inquiry should not be viewed exclusively as either a means or an end as such a view could lead to overestimating the importance of one aspect over the other (Abd-El-Khalick et al., 2004). Thus, when investigating inquiry in science education, attention should be given to inquiry as an instructional approach and inquiry as an instructional outcome (Abd-ElKhalick et al., 2004; NRC, 1996). 
Inquiry is far from a uniformly defined concept. Even after limiting the interpretation of inquiry as an instructional approach and outcome, multiple variations remain across studies. Rönnebeck, Bernholt, and Ropohl (2016) analyzed the variability of the range and type of inquiry found in the literature by looking into inquiry as single activities and a set of integrated activities. This framework of scientific inquiry consists of preparing, carrying out, explaining, evaluating, and communicating phases (see Figure 1). It explicitly acknowledges the importance of relating inquiry to student understanding about scientific concepts and the nature of science (Rönnebeck et al., 2016), which generally aligns with how inquiry is conceptualized in policy reforms (NRC, 2013; Rocard et al., 2007) as well TIMSS and PISA studies (Martin \& Mullis, 2013; Organisation for Economic Co-operation and Development [OECD], 2016a).

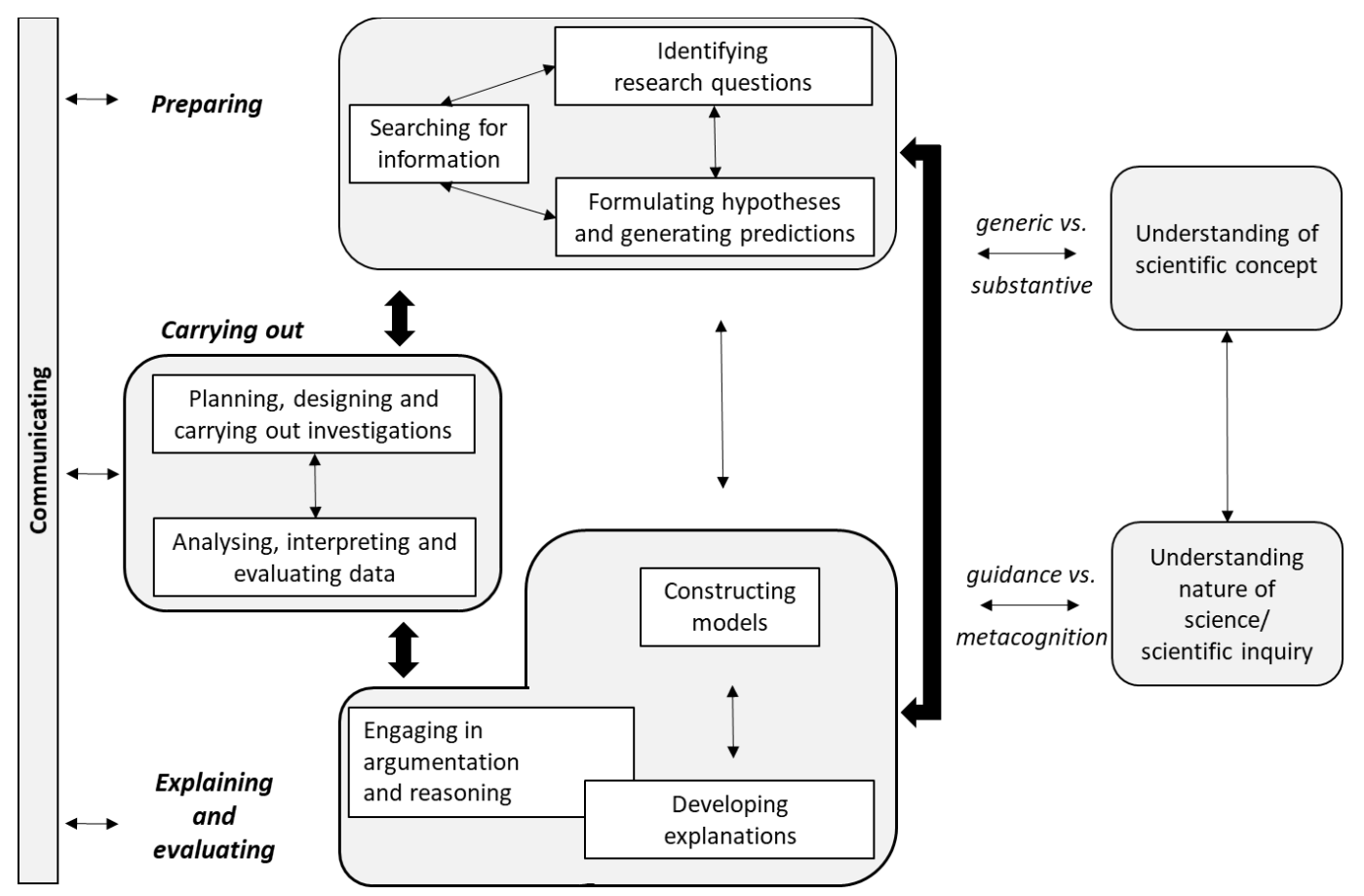

Figure 1. Conceptual framing of inquiry as an instructional approach and outcome in science. Reprinted from "Searching for a common ground-A literature review of empirical research on scientific inquiry activities," by S. Rönnebeck, S. Bernholt, and M. Ropohl, 2016, Studies in Science Education, 52, p. 189. CC BY.

Building on the Rönnebeck et al.'s inquiry framework (2016), the term inquiry as an instructional approach in the present study refers to single activities (e.g., interpreting data, constructing models, or developing scientific explanations) or a set of integrated activities or phases, such as designing and conducting experiments followed by analyzing, interpreting, and evaluating data from the experiments. As an instructional outcome, inquiry represents the competence to integrate scientific knowledge and reasoning skills implicated in the activity or a set of activities that are relevant for understanding science concepts and the nature of science. This dual conceptualization of inquiry can be identified in policy documents — such as the Next 
Generation Science Standards in the United States (NRC, 2013) or the Rocard report on science education in Europe (Rocard et al., 2007) - as well as the framework of science assessment in TIMSS and PISA (Martin \& Mullis, 2013; OECD, 2016a). While this section clarifies the conceptualization of inquiry as an instructional approach and outcome in science, the following sections compare how TIMSS and PISA studies assess both aspects of inquiry.

\section{The assessment of inquiry in TIMSS}

TIMSS is a quadrennial international comparative assessment that aims to measure trends in mathematics and science performance of students at the primary (Grade 4) and lower secondary (Grade 8) levels. The first cycle of TIMSS started in 1995 with only 45 participating countries whereas 64 countries participated in the last cycle in 2019. This section discusses how TIMSS measures inquiry as an instructional approach and outcome in science.

\section{Inquiry as an instructional approach}

The construct of inquiry as an instructional approach has never been explicitly defined in the TIMSS context questionnaire framework across cycles. For instance, the TIMSS 2015 and 2019 frameworks refer to inquiry as an essential part of instructional engagement in a classroom context (Martin \& Mullis, 2013; Mullis \& Martin, 2017). Here, instructional engagement is conceptualized with regard to the three basic dimensions of instructional quality: classroom management, supportive climate, and cognitive activation (Klieme, Pauli, \& Reusser, 2009). More specifically, inquiry activities were associated with cognitive activation that provides students with opportunities to engage in challenging tasks, such as working with others on a science project or discussing the results of an investigation (Martin \& Mullis, 2013; National Research Council, 2012). Apart from the TIMSS 1999 video study, inquiry has been measured together with other types of science teaching and learning activities using student and/or teacher questionnaires in primary schools (Grade 4) as well as secondary schools (Grade 8) across the cycles.

By applying the conceptual framework of inquiry as an instructional approach from Figure 1, the following table compares various items that were considered as part of the assessment of inquiry as an instructional approach in the fourth and eighth grade classrooms in TIMSS 2015 and 2019. Due to space limitation, a full comparison of inquiry assessment across all TIMSS cycles is presented in the Supplementary Material (Table S1). The TIMSS questionnaires ask students and/or teachers how often various types of inquiry activities occur in their science classrooms, with response options that typically range from "never", "some lessons", "about half the lessons" to "every or almost every lesson". See details about the development of ILSA questionnaires in Chapter 3.1.5. 
Table 1. The assessment of inquiry as an instructional approach using student and teacher questionnaires in TIMSS 2015 and 2019.

\begin{tabular}{|c|c|c|c|c|}
\hline \multirow{2}{*}{$\begin{array}{l}\text { TIMSS } \\
\text { cycle }\end{array}$} & \multicolumn{2}{|c|}{ Student questionnaire } & \multicolumn{2}{|c|}{ Teacher questionnaire } \\
\hline & Grade 4 & Grade 8 & Grade 4 & Grade 8 \\
\hline 2015 & N/A & N/A & $\begin{array}{l}\text { In teachir } \\
\text { how ofter } \\
\text { 1. Liste } \\
\text { 2. Obse } \\
\text { what } \\
\text { 3. Watc } \\
\text { inves } \\
\text { 4. Desi } \\
\text { 5. Conc } \\
\text { 6. Prese } \\
\text { inves } \\
\text { 7. Inter } \\
\text { inves } \\
\text { 8. Use } \\
\text { inves }\end{array}$ & $\begin{array}{l}\text { e students in this class, } \\
\text { em to do the following? } \\
\text { new science content. } \\
\text { nomena and describe } \\
\text { ate an experiment or } \\
\text { riments or investigations. } \\
\text { ts or investigations. } \\
\text { xperiments or } \\
\text { experiments or } \\
\text { experiments or } \\
\text { oport conclusions. }\end{array}$ \\
\hline 2019 & \multicolumn{2}{|c|}{$\begin{array}{l}\text { In science lessons, how often does your teacher } \\
\text { ask you to conduct science experiments? }\end{array}$} & \multicolumn{2}{|c|}{$\begin{array}{l}\text { In teaching science to the students in this class, } \\
\text { how often do you ask them to do the following? } \\
\text { 1. Listen to me explain new science content. } \\
\text { 2. Observe natural phenomena and describe } \\
\text { what they see. } \\
\text { 3. Watch me demonstrate an experiment or } \\
\text { investigation. } \\
\text { 4. Design or plan experiments or investigations. } \\
\text { 5. Conduct experiments or investigations. } \\
\text { 6. Present data from experiments or } \\
\text { 7. Investigations. } \\
\text { interpret data from experiments or } \\
\text { Use evidence from experiments or } \\
\text { investigations to support conclusions. }\end{array}$} \\
\hline
\end{tabular}

a The response options range from "never", "a few times a year", "once or twice a month" to "at least once a week".

As shown in Tables 1 and S1, the types of inquiry activities and the population being assessed vary across the TIMSS cycles. Activities related to teacher demonstration, student observation of natural phenomena, and student-led experimentation or investigation were consistently assessed across the cycles albeit with a slightly different item formulation. For instance, TIMSS 1995 asked students how often this activity happen in their science lessons: "We ourselves do an experiment or practical investigation in class". In TIMSS 1999, on the other hand, students were asked, "How often does your teacher ask you to conduct science experiments?". Some inquiry activities were excluded from the questionnaire in the recent TIMSS cycles even though they are aligned with current reforms in science education, such as the publications of A Framework for K-12 Science Education (NRC, 2012) and the Next Generation Science Standards (NRC, 2013). These activities include "explain the reasoning behind an idea" and "represent and analyze relationships using tables, charts, or graph" from TIMSS 1995 and 
1999 as well as "formulate hypotheses or predictions to be tested" and "learn about the nature of science and inquiry" from TIMSS 2003. Starting with TIMSS 2007, the inquiry activities being assessed in the questionnaire became more similar compared to the previous cycles, especially by emphasizing the activities related to teacher demonstration as well as student observation and scientific experimentation.

Although the inquiry activities assessed in the recent cycles are nearly identical, the target population be assessed varies significantly (see Table S1). In TIMSS 1995, students in Grades 3, 4, 7, and 8 as well as Grade 8 teachers were the target population while in TIMSS 1999 only the eighth-grade students and their teachers responded to the questions. In TIMSS 2003 and 2007, students in Grades 4 and 8 as well as their teachers were the target population whereas in TIMSS 2011 and 2015 only the teachers responded to the inquiry questions. In the latest cycle, TIMSS 2019, fourth and eighth grade students were given one item about how often they conduct science experiments while their teachers were given questions identical to those in TIMSS 2015. Both student and teacher responses are important for assessing inquiry as an instructional approach. Due to the TIMSS assessment design in which intact classes of students are sampled within a school (further details can be found in Chapter 3.1.1), student responses can be aggregated to the classroom level to reflect shared perceptions of the learning activities, correcting for irregularities in individual perception (Kunter \& Baumert, 2006). Even though teacher responses may be more prone to social desirability bias, research has shown that teachers could identify cognitively challenging instructional approaches better than their students (e.g., Kunter \& Baumert, 2006). Thus, asking both students and teachers about their perceptions of inquiry is crucial to improve the assessment of inquiry as an instructional approach in TIMSS.

\section{Inquiry as an instructional outcome}

TIMSS is a curriculum-based assessment that measures students' science knowledge as well as their understanding of and skills in science practices (Mullis \& Martin, 2017). TIMSS science assessment framework is designed and updated continuously to reflect the curricula of the participating countries. As shown in Table 2, few differences exist in the frameworks across the cycles. At each grade, the framework is organized around two dimensions: content domain and cognitive domain (initially referred to as performance expectations in TIMSS 1995 and 1999). There were several changes with respect to these dimensions in the first three cycles of TIMSS. In TIMSS 1995 and 1999, the nature of science-an essential aspect of scientific inquiry - was directly assessed as "environmental issues and the nature of science" under the content domain. However, in TIMSS 2003, this aspect was excluded and the list of performance expectations from the previous cycles was simplified into the cognitive domain. Since TIMSS 2007, there have been no significant changes in either the content or cognitive domains. 
Table 2. The framework of science assessment across TIMSS cycles

\begin{tabular}{|c|c|c|c|}
\hline \multirow{3}{*}{$\begin{array}{l}\text { TIMSS } 1995 \\
\text { and } 1999\end{array}$} & \multicolumn{2}{|c|}{ Content domain } & Performance expectations \\
\hline & Grade 4 & Grade 8 & Grades 4 and 8 \\
\hline & $\begin{array}{ll}\text { 1. } & \text { Earth science } \\
\text { 2. Life science } \\
\text { 3. Physical science } \\
\text { 4. Environmental issues } \\
\text { and the nature of } \\
\text { science }\end{array}$ & $\begin{array}{l}\text { 1. Earth science } \\
\text { 2. Life science } \\
\text { 3. Physics } \\
\text { 4. } \text { Chemistry } \\
\text { 5. Environmental issues } \\
\text { and the nature of } \\
\text { science }\end{array}$ & $\begin{array}{l}\text { 1. Understanding simple } \\
\text { information } \\
\text { 2. Understanding complex } \\
\text { information } \\
\text { 3. Theorizing, analyzing, } \\
\text { and solving problems } \\
\text { 4. Using tools, routines } \\
\text { procedures, and science } \\
\text { processes } \\
\text { 5. Investigating the } \\
\text { natural world }\end{array}$ \\
\hline \multirow[t]{3}{*}{ TIMSS 2003} & \multicolumn{2}{|c|}{ Content domain } & Cognitive domain \\
\hline & Grade 4 & Grade 8 & Grades 4 and 8 \\
\hline & $\begin{array}{ll}\text { 1. } & \text { Earth science } \\
\text { 2. Life science } \\
\text { 3. Physical science } \\
\text { 4. Environmental science }\end{array}$ & $\begin{array}{ll}\text { 1. } & \text { Earth science } \\
\text { 2. Life science } \\
\text { 3. Physics } \\
\text { 4. Chemistry } \\
\text { 5. Environmental science }\end{array}$ & $\begin{array}{l}\text { 1. Factual knowledge } \\
\text { 2. Conceptual } \\
\text { understanding } \\
\text { 3. Reasoning and analysis }\end{array}$ \\
\hline $\begin{array}{l}\text { TIMSS 2007, } \\
\text { 2011, 2015, } \\
\text { and } 2019\end{array}$ & $\begin{array}{ll}\text { 1. } & \text { Earth science } \\
\text { 2. } & \text { Life science } \\
\text { 3. } & \text { Physical science }\end{array}$ & $\begin{array}{ll}\text { 1. } & \text { Earth science } \\
\text { 2. } & \text { Physics } \\
\text { 3. } & \text { Chemistry } \\
\text { 4. } & \text { Biology }\end{array}$ & $\begin{array}{ll}\text { 1. } & \text { Knowing } \\
\text { 2. } & \text { Applying } \\
\text { 3. } & \text { Reasoning }\end{array}$ \\
\hline
\end{tabular}

In each cycle, TIMSS framework emphasizes the central role of inquiry as an instructional outcome. Rather than assigning inquiry under one of the domains, TIMSS places inquiry as an overarching assessment strand that overlaps in both the content and cognitive domains (Mullis $\&$ Martin, 2017). Students are expected to have general knowledge about the nature of science and scientific inquiry as well as to demonstrate the skills and abilities pertinent to the inquiry process including (1) formulating questions and hypotheses, (2) designing investigations, (3) representing data, (4) analyzing and interpreting data, and (5) drawing conclusions and developing explanations (Mullis, Martin, Ruddock, O'Sullivan, \& Preuschoff, 2009, p. 88). Following reforms in science education including policy recommendations in A Framework for K-12 Science Education (NRC, 2012) and the Next Generation Science Standards (NRC, 2013), the term scientific inquiry as the overarching strand of the science assessment was expanded into science practices in TIMSS 2015. Science practices include skills from everyday life and school science that are used to conduct scientific inquiry in a systematic way: (1) asking questions based on observations, (2) generating evidence, (3) working with data, (4) answering a research question, and (5) making an argument from evidence (Martin \& Mullis, 2013, p. 58). Similar to the notion of scientific inquiry from the previous TIMSS frameworks, science practices were not assessed in isolation. Instead, they were assessed in relation to science content domains (i.e., biology, chemistry, physics, and earth science) and by drawing upon a range of thinking processes specified in the cognitive domains of knowing, applying, and reasoning. Inquiry as an instructional outcome is highly emphasized within the reasoning 
domain, which requires students to analyze information, design investigations, use evidence to justify explanations, evaluate alternative explanations, and extend their understandings in new situations (Klieme et al., 2009; Martin \& Mullis, 2013, p. 56).

As of 2019, TIMSS has transitioned to a digitally based assessment called eTIMSS that was administered via computers or tablets (Mullis \& Martin, 2017). eTIMSS introduces additional innovative problem solving and inquiry tasks (PSIs) by simulating real-world problems that allow students to interact with digital environments and apply a wide range of science knowledge to solve them (Mullis \& Martin, 2017). PSIs assess science practices including the skills that are relevant for conducting scientific inquiry and investigation, such as testing hypotheses and exploring relationships between variables (Mullis \& Martin, 2017). Compared to the previous paper-based testing, the use of interactive and dynamic tasks in eTIMSS can contribute to a more effective assessment of students' complex problem solving and inquiry skills.

\section{The assessment of inquiry in PISA}

PISA is a triennial study designed to evaluate education systems worldwide by assessing the skills and competencies of 15-year-old students, with core domains in reading, mathematics, and science. The study domains rotate each cycle, and science was the core domain in PISA 2006 and 2015. PISA only assesses inquiry as an instructional approach when science is the core domain of assessment whereas inquiry as an instructional outcome is assessed as part of science assessment in each cycle starting in PISA 2000. This section summarizes how PISA measures inquiry as an instructional approach and outcome in science.

\section{Inquiry as an instructional approach}

In contrast to TIMSS, PISA assessment and analytical framework explicitly specifies the assessment of inquiry as an instructional approach under the umbrella of "enquiry-based science instruction". In PISA 2015, the construct was conceptualized as "the ways in which scientists study the natural world, propose ideas, and explain and justify assertions based upon evidence derived from scientific work" which includes "engaging students in experimentation and hands-on activities, and also [...] encouraging them to develop a conceptual understanding of scientific ideas" (OECD, 2016b, p. 69). Unlike TIMSS, which measures inquiry as an instructional approach using student and/or teacher questionnaires, PISA only measures inquiry using a student questionnaire. However, 19 participating countries and economies also included a teacher questionnaire in PISA 2015. Nevertheless, a direct link between students' and their teachers' responses cannot be established due to the PISA design that samples students within a school rather than intact classes of students within a school, as in TIMSS (for details see Chapter 3.1.1). As such, PISA assesses students' perceptions about inquiry activities in their school rather than classroom science lessons, and these perceptions can only be linked to the teachers' perceptions at the school level. Furthermore, these students may or may not have taught by the same teachers who answered the questionnaire because the teachers were also randomly sampled within a school. 
Table 3 shows a comparison of the items that were used to assess the implementation of inquiry as an instructional approach in PISA 2006 and 2015. PISA asks students and teachers how often various types of inquiry activities occur in their school science lessons by selecting "never or hardly ever," "in some lessons," "in most lessons," or "all lessons".

Table 3. The assessment of inquiry as an instructional approach in PISA 2006 and 2015.

\begin{tabular}{|c|c|c|}
\hline PISA 2006 & \multicolumn{2}{|c|}{ PISA 2015} \\
\hline Student questionnaire & Student questionnaire & $\begin{array}{l}\text { Teacher questionnaire } \\
\text { (optional) }^{\mathrm{a}}\end{array}$ \\
\hline $\begin{array}{l}\text { When learning science topics at school, how often } \\
\text { do the following activities occur? } \\
\text { 1. Students are given opportunities to explain } \\
\text { their ideas } \\
\text { 2. Students spend time in the laboratory doing } \\
\text { practical experiments } \\
\text { 3. Students are required to design how a science } \\
\text { question could be investigated in the laboratory } \\
\text { 4. The students are asked to apply a science } \\
\text { concept to everyday problems } \\
\text { 5. The lessons involve students' opinions about } \\
\text { the topics } \\
\text { 6. Students are asked to draw conclusions from } \\
\text { an experiment they have conducted } \\
\text { 7. "The teacher explains how a <social science> } \\
\text { idea can be applied to a number of different } \\
\text { phenomena (e.g. the movement of objects, } \\
\text { substances with similar properties)" } \\
\text { 8. Students are allowed to design their own } \\
\text { experiments } \\
\text { 9. There is a class debate or discussion } \\
\text { 10. Experiments are done by the teacher as } \\
\text { demonstrations } \\
\text { 11. Students are given the chance to choose their } \\
\text { own investigations } \\
\text { 12. The teacher uses <school science> to help } \\
\text { students understand the world outside school } \\
\text { 13. Students have discussions about the topics } \\
\text { 14. Students do experiments by following the } \\
\text { instructions of the teacher } \\
\text { 15. The teacher clearly explains the relevance of } \\
\text { <broad science> concepts to our lives } \\
\text { 16. Students are asked to do an investigation to test } \\
\text { out their own ideas } \\
\text { application to show how <school science> is } \\
\text { relevant to society }\end{array}$ & $\begin{array}{l}\text { When learning <school } \\
\text { science> topics at school, } \\
\text { how often do the } \\
\text { following activities } \\
\text { occur? } \\
\text { 1. Students are given } \\
\text { opportunities to } \\
\text { explain their ideas. } \\
\text { 2. Students spend time } \\
\text { in the laboratory } \\
\text { doing practical } \\
\text { experiments. } \\
\text { 3tudents are asked to } \\
\text { draw conclusions } \\
\text { from an experiment } \\
\text { they have conducted. } \\
\text { The teacher explains } \\
\text { how a <school } \\
\text { science> idea can be } \\
\text { applied to a number } \\
\text { of different } \\
\text { phenomena (e.g. the } \\
\text { movement of objects, } \\
\text { substances with } \\
\text { similar properties). } \\
\text { Students are allowed } \\
\text { to design their own } \\
\text { experiments. } \\
\text { There is a class } \\
\text { debate about } \\
\text { investigations. } \\
\text { The teacher clearly } \\
\text { explains the } \\
\text { relevance of <broad } \\
\text { science> concepts to } \\
\text { our lives. } \\
\text { Students are asked to } \\
\text { do an investigation to } \\
\text { test ideas. }{ }^{\text {b }} \\
\text { to argue about } \\
\text { science questions. }\end{array}$ & $\begin{array}{l}\text { How often do these things } \\
\text { happen in your <school } \\
\text { science> lesson? } \\
\text { 1. Students are asked to } \\
\text { draw conclusions } \\
\text { from an experiment } \\
\text { they have conducted. } \\
\text { 2. Students are given } \\
\text { opportunities to } \\
\text { explain their ideas. } \\
\text { 3. } \begin{array}{l}\text { Current scientific } \\
\text { issues are discussed. } \\
\text { 4. Students make } \\
\text { calculations using } \\
\text { scientific formulas. } \\
\text { 5. Students do their own } \\
\text { scientific study and } \\
\text { related research. } \\
\text { 6. Students carry out } \\
\text { practical work. } \\
\text { 7. Students write up } \\
\text { laboratory reports. }\end{array}\end{array}$ \\
\hline
\end{tabular}

${ }^{a}$ An optional teacher questionnaire that was used in 19 participating countries and economies.

${ }^{\mathrm{b}}$ Revised item from the student questionnaire in PISA 2006.

${ }^{\mathrm{c}}$ New items in PISA 2015. 
More than half of the items that measured inquiry as an instructional approach in PISA 2006 were excluded from PISA 2015. In this last cycle of science assessment, only nine items were used to assess inquiry. Compared to PISA 2006, it includes six identical items (e.g., "students are given opportunities to explain their ideas"), two modified items ("students are allowed to design their own experiment" and "there is a class debate about investigations"), and one new item ("students are required to argue about science questions). PISA 2015 also asked teachers some of these inquiry items in the optional teacher questionnaire for those countries that opted to include it in the assessment. In contrast to TIMSS, inquiry activities assessed in PISA are more varied. PISA assesses not only activities related to student experiment or investigation but also critique and argumentation, such as those that require students to argue about science questions or engage in class debate. Although many of the inquiry activities in PISA and TIMSS are overlapped, PISA includes a more diverse range of activities in assessing of inquiry as an instructional approach compared to TIMSS.

\section{Inquiry as an instructional outcome}

PISA is a literacy-based assessment that measures students' scientific literacy. Similar to TIMSS, PISA does not assess inquiry as an instructional outcome in isolation. Instead, it assesses inquiry in relation to various aspects of scientific literacy. Table 4 shows the evolution of the definition of scientific literacy in PISA. In PISA 2000 and 2003, inquiry is closely related to scientific process or skills that are involved in identifying questions and explaining conclusions. In PISA 2006, 2009, and 2012, however, inquiry is more apparent in the competencies relevant for understanding scientific knowledge and features of science as a form of human knowledge as well as engaging in science-related issues (OECD, 2006, 2016a). In the last two cycles of PISA, the assessment of inquiry as an instructional outcome was largely represented under the competencies in evaluating and designing scientific enquiry and interpreting data and evidence scientifically (OECD, 2016a).

Table 4. The definition of scientific literacy across PISA cycles (OECD, 2006, 2016a).

\begin{tabular}{|c|c|c|}
\hline PISA 2000 and 2003 & PISA 2006, 2009, and 2012 & PISA 2015 and 2018 \\
\hline $\begin{array}{l}\text { The capacity to use scientific } \\
\text { knowledge, to identify questions } \\
\text { and to draw evidence-based } \\
\text { conclusions in order to understand } \\
\text { and help make decisions about the } \\
\text { natural world and the changes } \\
\text { made to it through human activity. }\end{array}$ & $\begin{array}{l}\text { The extent to which an individual: } \\
\text { - } \quad \text { possess scientific knowledge } \\
\text { and use of that knowledge to } \\
\text { identify questions, acquire } \\
\text { new knowledge, explain } \\
\text { scientific phenomena and } \\
\text { draw evidence-based } \\
\text { conclusions about science- } \\
\text { related issues } \\
\text { understand of the } \\
\text { characteristic features of } \\
\text { science as a form of human } \\
\text { knowledge and enquiry } \\
\text { shows awareness of how } \\
\text { science and technology shape } \\
\text { our material, intellectual, and } \\
\text { cultural environments }\end{array}$ & $\begin{array}{l}\text { The ability to engage with science- } \\
\text { related issues, and with the ideas } \\
\text { of science, as a reflective citizen. } \\
\text { A scientifically literate person is } \\
\text { willing to engage in reasoned } \\
\text { discourse about science and } \\
\text { technology, which requires the } \\
\text { competencies to: } \\
\text { - Explain phenomena } \\
\text { scientifically - recognize, } \\
\text { offer and evaluate } \\
\text { explanations for a range of } \\
\text { natural and technological } \\
\text { phenomena. } \\
\text { Evaluate and design scientific } \\
\text { enquiry - describe and } \\
\text { appraise scientific }\end{array}$ \\
\hline
\end{tabular}




\begin{tabular}{|l|l|l|}
\hline & $\begin{array}{l}\text { engage in science-related } \\
\text { issues and with the ideas of } \\
\text { science, as a reflective citizen. }\end{array}$ & $\begin{array}{l}\text { investigations and propose } \\
\text { ways of addressing questions } \\
\text { scientifically. } \\
\text { Interpret data and evidence } \\
\text { scientifically - analyze and } \\
\text { evaluate data, claims and } \\
\text { arguments in a variety of } \\
\end{array}$ \\
& $\begin{array}{l}\text { representations and draw } \\
\text { appropriate scientific } \\
\text { conclusions. }\end{array}$ \\
\hline
\end{tabular}

The assessment of inquiry as an instructional outcome has undoubtedly a central place in both TIMSS and PISA frameworks. However, since these studies emphasize different types of assessment focus (i.e., curriculum-based versus literacy-based), it is challenging to compare the extent to which inquiry is covered in both studies. Due to the literacy approach of PISA, this assessment is assumed to be independent from the science curricula in the participating countries. As shown in Table 4, PISA focuses on assessing whether 15-year-old students have acquired the "knowledge and skills for full participation in modern society" within the common, internationally agreed framework of scientific literacy (OECD, 2016a, p. 1). Consequently, this assessment provides in great detail about what it means to be a scientifically literate individual, including the place of inquiry in the framework.

Starting from 2015, PISA has administered computer-based assessment to assess scientific literacy. The use of interactive and simulated environments has enhanced the assessment of inquiry in comparison to the previous cycles. For example, students are required to conduct an investigation by manipulating a number of variables in a simulated experiment to generate evidence that support their arguments. Unlike TIMSS, PISA also assesses students' noncognitive outcomes that are relevant for inquiry through the student questionnaire. Specifically, PISA 2006 assessed students' support for scientific inquiry while PISA 2015 included the assessment of their epistemological beliefs. Thus, although student understanding of science knowledge is greatly covered by both studies, the assessment of scientific inquiry, particularly the nature of science, is more evident in the PISA framework than in its TIMSS counterpart.

\section{The Present Study}

The present study sets out to review studies utilizing TIMSS and PISA data to investigate inquiry in science education. Following the conceptualization of inquiry as an instructional approach and outcome described in the previous section, these studies can be mapped into the Scheerens's (1990) Context-Input-Process-Output (CIPO) model of schooling. As shown in Figure 2, the CIPO-model places inquiry aspects from TIMSS and PISA frameworks by focusing on inquiry as an essential part of school science context, which includes the input (e.g., student characteristics), the process (i.e., the perceptions of inquiry at the class and school level), and the output (i.e., overall science achievement including scientific skills and the nature of science). 


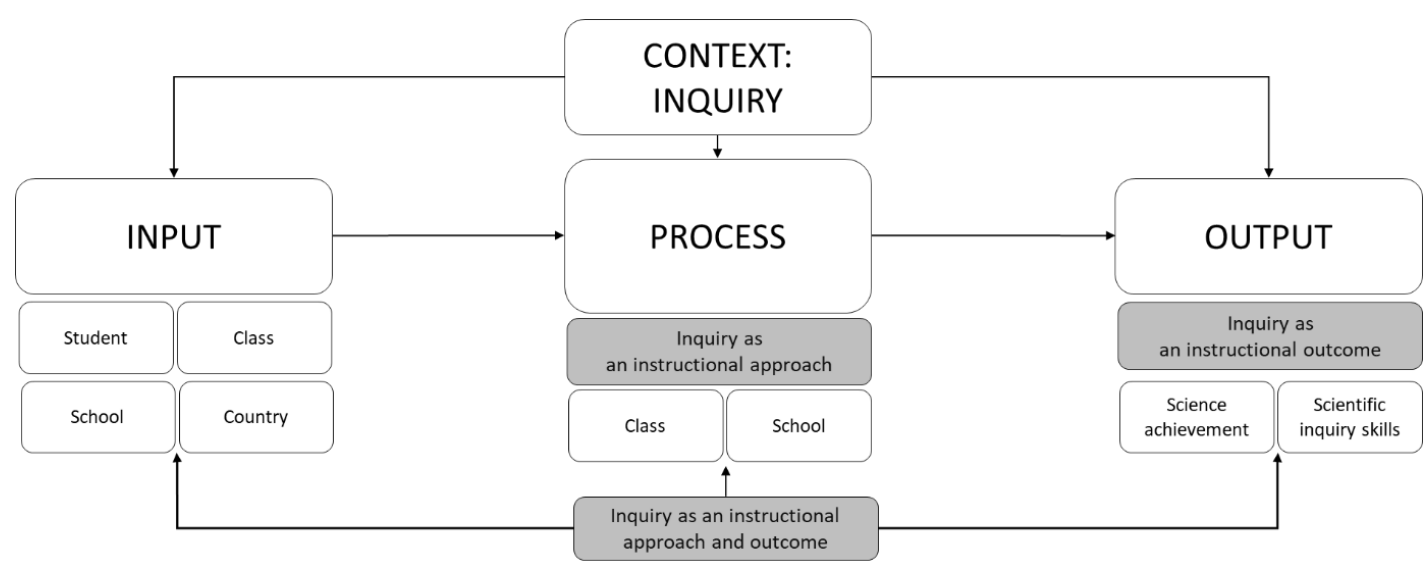

Figure 2. An overview of three strands of inquiry research: (1) inquiry as an instructional approach, (2) inquiry as an instructional outcome, and (3) inquiry as an instructional approach and outcome using the CIPO-model.

Using the CIPO-model, the studies that investigate inquiry using TIMSS and PISA data can be classified into three strands of research: (1) inquiry as an instructional approach that focuses on examining different types of inquiry input — such as student or teacher characteristics - to explain the implementation of inquiry perceived at the class or school level, (2) inquiry as an instructional outcome that focuses on explaining the differences in students' inquiry output, either as overall science achievement or specific scientific inquiry skills, and (3) inquiry as an instructional approach and outcome that focuses on the relationships between the input, process, and output of inquiry. Accordingly, the present study reviews the three strands of inquiry research by specifically addressing the following research questions (RQs):

1. What are the main characteristics of the studies investigating inquiry using TIMSS and PISA data?

2. How did the findings from these studies contribute to the existing research on inquiry in science education?

To address RQ1, this study summarizes the similarities and differences across the studies that used TIMSS and PISA data to investigate inquiry by focusing on (1) the aim of the studies, (2) the characteristics of the TIMSS and PISA data utilized in the studies, and (3) how the studies measured and analyzed inquiry. To address RQ2, findings from these studies are further synthesized across the three strands of inquiry research to identify the relevant factors that explain (1) teachers' frequent implementation of inquiry as an instructional approach, (2) students' performance in inquiry or inquiry as an instructional outcome, and (3) the relationships between inquiry as an instructional approach and outcome. Taken together, this review may provide an in-depth analysis of how researchers have leveraged TIMSS and PISA data to advance the three strands of inquiry research in science education.

\section{Methods}

A spectrum of approaches to systematically reviewing literature exists depending on the extent of the research problem, the scope and degree of detail needed, and the available time and resources to conduct it (Gough, Oliver, \& Thomas, 2017). Using systematic review approach, 
this study summarizes the ways in which TIMSS and PISA data have been used to investigate inquiry and to provide an overall view of the findings from the existing research. Even though the review process was performed individually rather than in a review team-as commonly practiced when conducting a systematic review - it followed clear, methodical, and accountable procedures to addresses the transparency and replicability of the review process (Gough et al., 2017).

\section{Literature search}

A literature search was conducted using the following databases: ERIC, PsycInfo, Scopus, EBSCO, and Web of Science. These five databases were chosen given their relevance to the field of educational research. The search was undertaken on April 2019 and then updated on April 9, 2020 using combinations of the key terms "PISA" or "Programme for International Student Assessment" or "Program for International Student Assessment" or "TIMSS" or "Trends in International Mathematics and Science Study" or "Trends in International Math and Science Study" and "inquiry" or "enquiry." The search in the databases was not restricted to a specific time range, but the publication was restricted to journal articles with English as the language of publication.

In addition to the database search, additional studies were also identified by screening relevant journals in the area of science education (i.e., International Journal of Science Education, International Journal of Science and Mathematics Education, Science Education, Journal of Research in Science Teaching, and Research in Science Education) and assessment (i.e., Large Scale Assessment, Applied Measurement in Education, and Assessment in Education and Educational Assessment). Furthermore, the snowball method was applied to identify additional studies based on several key articles that were already included in the review by scanning the reference section of these articles, tracking references that had cited these articles, and tracing publication lists of scholars from these articles.

\section{Inclusion criteria}

The following first-order criteria for including articles in the review process were set beforehand:

1. The article was published in a peer-reviewed academic journal. Other types of publications, including book chapter, thesis, conference paper, national or international report publishing TIMSS or PISA results were excluded.

2. The language of publication was English.

3. The article conducted a secondary analysis of TIMSS or PISA data. Studies that used non-regular data (e.g., TIMSS video study) were excluded.

4. The article was concerned with inquiry in science education by focusing on inquiry as an instructional approach or outcome (see details in Figure 2).

\section{Search and screening process}

As shown in Figure 3, after removing duplicate records, the initial search yielded altogether 197 articles. These articles were screened according to the inclusion criteria by scanning the titles and the abstracts. Of these 197 articles, only 71 articles were included to the next review 
process. In this step, the full-text articles were assessed following the inclusion criteria. Finally, a total of 51 articles were included for qualitative synthesis. Each of these articles was coded based on the three thematic aspects of research utilizing TIMSS or PISA data to investigate inquiry (see further details in The Present Study).

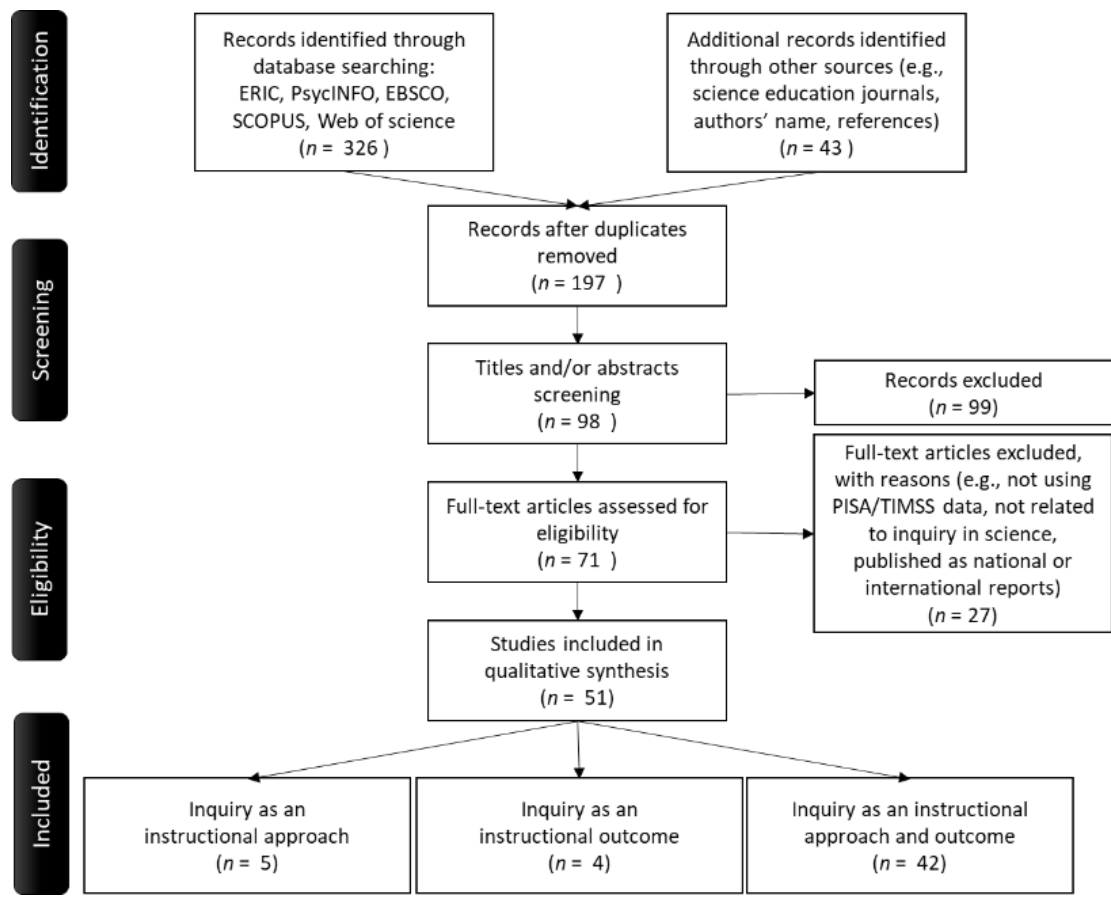

Figure 3. A flowchart of study selection in the review process.

\section{Findings}

The number of publications of inquiry research using TIMSS and PISA data seems to slightly increase each year with a small decrease in 2015 and 2018 (Figure 4). Note that the literature search was performed in April 2020 and only two articles published in 2020 were included in the review. Most articles were published in the International Journal of Science Education (13), followed by International Journal of Science and Mathematics Education (4), Research in Science Education (4), Journal of Research in Science Teaching (3), and Learning and Instruction (2).

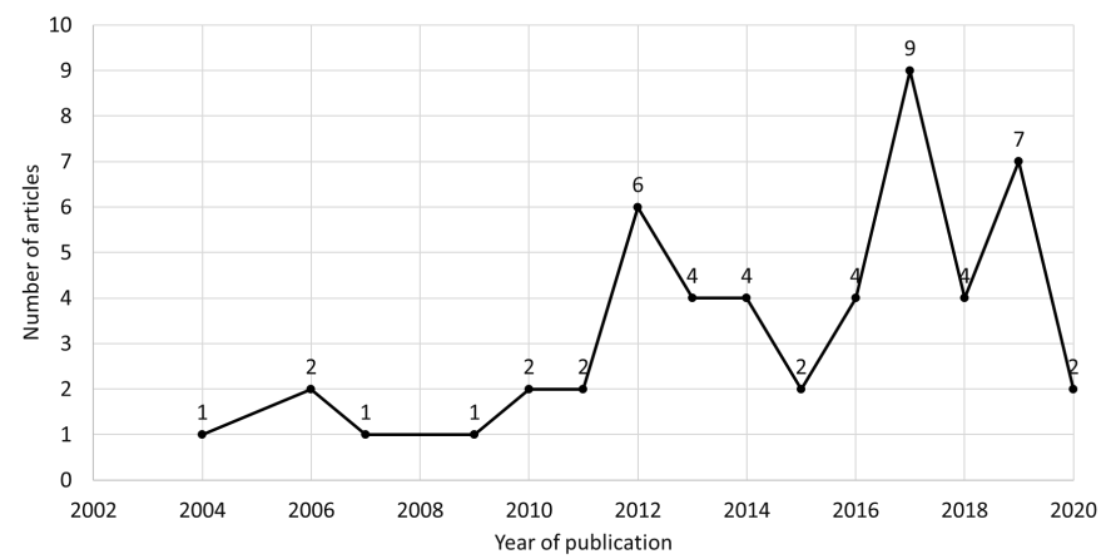

Figure 4. Frequency of published articles on inquiry in science education using TIMSS and PISA data over time. 


\section{RQ1: The main characteristics of the studies}

\section{Aim of the studies}

A total of 51 articles were included in the review. Five articles investigated the first strand of inquiry as an instructional approach by examining the characteristics of student (1), class or teacher (4), school (1), and country (1) as the input of inquiry and inquiry process at the classroom level (3) and school level (2). Teacher characteristics such as gender, education and professional development, teaching experience, and self-efficacy were frequently used as the input of inquiry. Four articles investigated inquiry as an instructional outcome focusing on the inquiry process at classroom level (2) and school level (2) and the output of inquiry, including the effects of item characteristics on the difficulties of inquiry items (2), student mastery of various inquiry skills (1), and gender differences in inquiry skills (1). The remaining 42 articles examined the relationships between inquiry as an instructional approach and outcome in science. These articles investigated the relationships between inquiry process and students' science achievement (42) at the classroom level (19) and school level (23).

\section{TIMSS and/or PISA data analyzed in the studies}

In general, 29 articles used TIMSS data from 1999-2015 and 27 articles used PISA data from 2000-2015, with the highest number of publications utilizing PISA 2006 followed by TIMSS 2007 and PISA 2015 (Figure 5). While the articles investigating inquiry as an instructional approach mostly used TIMSS data, the remaining stands of inquiry research were examined using both data almost equally. For the first strand of inquiry research, these studies analyzed data from student questionnaire (1) and teacher questionnaire (4), whereas only student science assessment was used in analyzing second strand of inquiry research (5). To examine the last strand of inquiry research, most studies used a combination of data from student questionnaire and science assessment (37), followed by teacher questionnaire and science assessment (5).

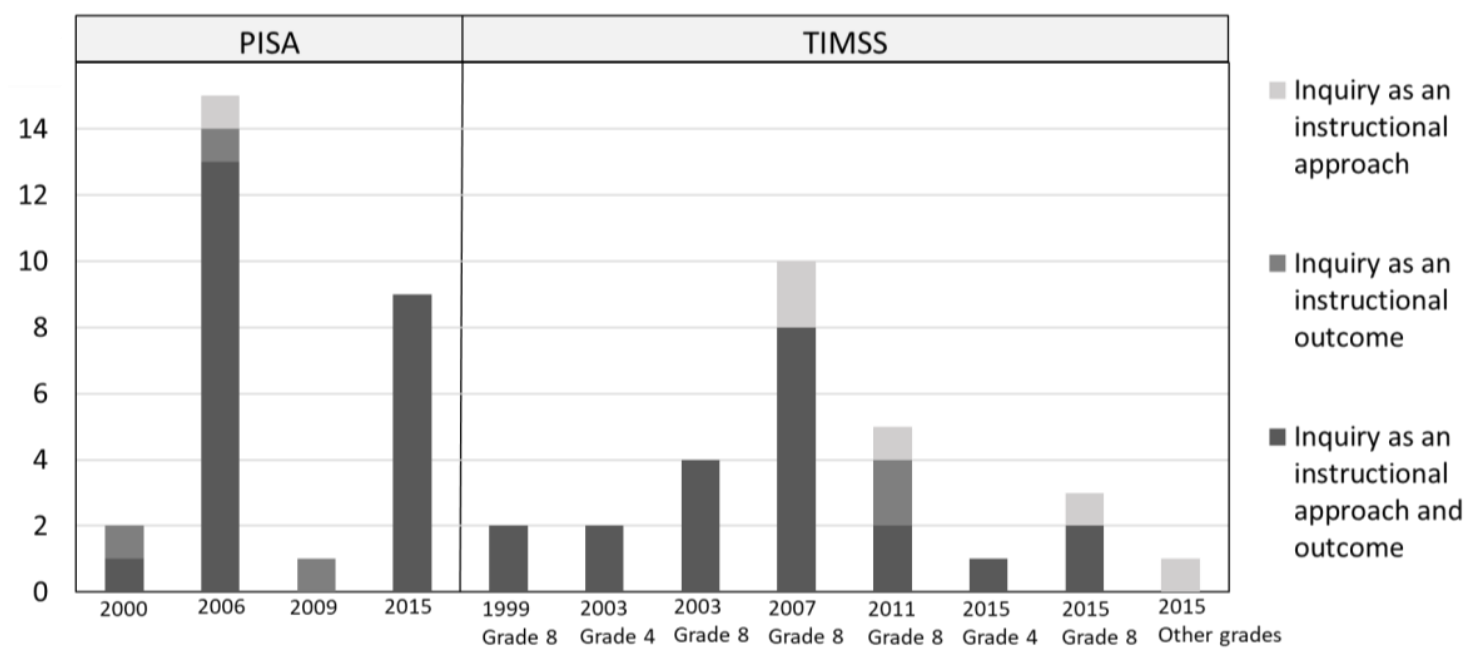

Figure 5. Frequency of published articles on inquiry in science education using TIMSS and PISA data across cycles and populations.

With respect to the country-level data, only 17 articles focused on investigating data from a single country compared to 34 articles that analyzed data from multiple countries. An overview of the countries from which TIMSS and PISA data were frequently used in the analyses can be 
found in the Supplementary Material (Figure S1). In general, data from the United States were most often analyzed (18), followed by Taiwan (14), Canada (13), Finland (12), and Japan (11). Single-country studies mostly examined data from the United States (6), Taiwan (5), and Turkey (4), whereas multi-country studies often included data from the United States (12), Canada (11), and Japan (11). Data from single countries were less utilized compared to multicountry data for research on inquiry as an instructional approach (1 vs. 4) and inquiry as an instructional approach and outcome (13 vs. 29). However, the opposite was found for research on inquiry as an instructional outcome (3 vs. 1).

\section{The measurement and analysis of inquiry}

The measurement of inquiry varies considerably across the articles. As an instructional outcome, inquiry was mostly measured using self-report from students rather than teachers (48 vs. 12). All studies included the activities related to conducting scientific investigation or experimentation. More than half of the studies also included other activities that are related to inquiry directly — such as observing natural phenomena, constructing scientific explanation, and arguing about science questions - and indirectly, including teachers explaining science concept, asking students to use scientific formula and laws, and relating the lesson to students' daily lives. Most studies treated students' or teachers' responses on these inquiry activities as a single scale by using the existing index from the TIMSS or PISA database (referred to as IBTEACH in PISA and Teachers Emphasize Science Investigation in TIMSS) or by averaging the responses in the selected inquiry activities (26), followed by implementing factor analysis (9), and analyzing the responses in each activity (7). As an instructional outcome, inquiry was mostly measured using overall science achievement (42), and specific scientific inquiry skills like designing investigations and drawing conclusions (4). In addition, some studies also separated overall science achievement into different types of cognitive abilities like knowing, applying, and reasoning (2), while other studies added non-cognitive outcomes, such as motivation and interest (8), attitudes towards science (2), science related-career aspiration (3), epistemological beliefs (2), and environmental awareness (1).

Similar to the measurement of inquiry, its analysis also differs significantly across the studies. In the first strand of inquiry research, linear regression methods (2) and latent variable approaches (2) were employed to explain the variations in inquiry as an instructional approach across students (3), classes (1), and countries (1). In the second strand of inquiry research, more diverse approaches were applied to analyze the differences in students' scientific inquiry skills, including regression methods (2), Rasch model (1), and general diagnostic model (1). To explain the relationship between inquiry as an instructional approach and science achievement in the last strand of inquiry research, most studies again employed linear regression methods (27) and latent variable approaches (10). These studies analyzed the relationship between inquiry as an instructional approach and outcome at the student (17), class (8), school (10), and country level (7). It should be emphasized that only one study found in this review linked ILSAs data (i.e., PISA) with student prior achievement using a longitudinal design and thereby providing causal inferences about the relationships among variables. The majority of studies considered the clustering of students in the analyses, students are nested within classes in TIMSS and students are nested within schools in PISA, but about one third of the studies failed 
to take into account the multilevel nature of these data. Furthermore, all studies analyzed the relationship between inquiry approach and science achievement linearly, whereas three studies also added the investigation of non-linear relationships.

\section{RQ2: Contribution of the studies to the research on inquiry in science education}

In general, secondary analysis of TIMSS and PISA data contributes to the existing knowledge on inquiry in science education, as they provide unique opportunities for generalizing the findings to a wide population. This section summarizes how these findings specifically contribute to the three strands of inquiry research by identifying relevant factors that explain (1) teachers' frequent implementation of inquiry as an instructional approach, (2) students' performance in inquiry or inquiry as an instructional outcome, and (3) the relationships between inquiry as an instructional approach and outcome.

\section{Inquiry as an instructional approach}

In line with mainstream research in science education (e.g., Chichekian \& Shore, 2016), teacher/class characteristics were the potential input factors in explaining the variations of inquiry as an instructional approach. Most studies found teachers' backgrounds - such as the amount of teaching experience and educational level—and beliefs, especially their confidence in teaching science and attitude toward academic collaboration, were significantly associated with frequent implementation of inquiry activities, no association existed with regards to teachers' participation in professional development (e.g., Kang \& Keinonen, 2016; Pongsophon \& Herman, 2017; Teig et al., 2019). In contrast, teachers who reported strong challenges related to time constraint, large class size, or inadequate teaching resources also implemented inquiry instruction less often (e.g., Pongsophon \& Herman, 2017; Teig et al., 2019). Although the strength of the relationships varied across these studies, the findings seem to be robust across ILSA cycles, countries, and grades.

\section{Inquiry as an instructional outcome}

Four studies identified in this category showed that item characteristics could explain performance differences in scientific inquiry skills. Overall, students had difficulties in solving inquiry problems that involved abstract ideas, used large amounts of irrelevant resources (e.g., text, graphics), and required procedural instead of declarative or schematic knowledge (RuizPrimo \& $\mathrm{Li}, 2016$ ). Items with constructed responses were also more difficult for students to solve, especially those that tapped into reasoning compared to other cognitive domains like knowing and applying (Liou \& Bulut, 2017). Similarly, Kabiri et al. (2017) found that students encounter considerable challenges to solve items that require complex and high-order thinking skills like reasoning, conducting scientific inquiry, and explaining phenomena scientifically. Additionally, although no gender differences were found in the overall scores of scientific inquiry, girls had significantly higher performance in recognizing scientific questions and identifying evidence while boys tended to perform better in understanding scientific concepts (Yip et al., 2004). Studies in this category generally support current research that examine potential sources of difficulties in science assessment (e.g., Collier, Morell, \& Wilson, 2018) while at the same time advancing this topic by focusing on specific scientific inquiry skills. 


\section{Inquiry as an instructional approach and outcome}

All studies identified in this category focused on investigating the relationships between inquiry as an instructional approach and outcome. While the findings generally demonstrated a positive association between inquiry instruction and students' non-cognitive outcomes, such as motivation, interest, and attitude towards science (e.g., Cairns \& Areepattamannil, 2017; Jiang $\&$ Mccomas, 2015), there were mixed findings in relation to the cognitive outcomes.

These differences can be traced to several factors associated with how these studies measured and analyzed inquiry. First, various types and ranges of inquiry activities were used to measure inquiry as an instructional approach. Some studies only focused on student centered-activities (e.g., Jerrim et al., 2019; Teig, Scherer, \& Nilsen, 2018) while other studies also included teacher directed-instruction, such as teacher explaining how a science idea can be applied to different phenomena or relating what students are learning in science to their daily lives (e.g., Cairns, 2019; Forbes, Neumann, \& Schiepe-Tiska, 2020; Gao, 2014). Second, even when the studies used identical items to measure inquiry, there were vast differences in the ways these activities were represented in the analyses. While the majority of the studies utilized a single scale of inquiry that combined student and teacher led-activities (e.g., Cairns \& Areepattamannil, 2017; Kaya \& Rice, 2010; Tang, Tsai, Barrow, \& Romine, 2018), others took into account these differences, either by analyzing them as individual inquiry items (e.g., Cairns, 2019; Oliver, McConney, \& Woods-McConney, 2019) or combining similar items into the same groups, such as by referring them as guided and independent inquiry (Aditomo \& Klieme, 2020; Jiang \& Mccomas, 2015). The different ways to measure and analyze inquiry as an instructional approach found across these studies also reflects the state of science education research in general, which has long debated how to conceptualize inquiry and what it means to teach science as inquiry (Crawford, 2014; Furtak \& Penuel, 2019). In addition, inquiry in ILSA studies was analyzed at different levels - across students, classes, schools, or countries - which contributes to the difficulty in identifying the types of inquiry activities that were associated with highest science achievement.

Although it remains challenging to compare the findings, some similar patterns existed across the studies. In general, studies that measured inquiry activities using a single scale found a negative relationship between inquiry and science achievement (e.g.,Cairns \& Areepattamannil, 2017; Chi, Liu, Wang, \& Won Han, 2018; Kaya \& Rice, 2010). However, this relationship also varied across different types of inquiry activities. Higher frequencies of teacher led-activities, such as explaining science ideas or the relevance of science concepts to everyday lives, were related to higher science achievement (e.g., Cairns, 2019; Gao, 2014; Lavonen \& Laaksonen, 2009). In contrast, students who reported more frequent use of student-led activities, particularly those that are related to conducting independent scientific investigations (e.g., students design experiments or engage in a class debate about investigations) had lower achievement (e.g., Jiang \& Mccomas, 2015; Kaya \& Rice, 2010; Lau \& Lam, 2017; Lavonen \& Laaksonen, 2009). The strongest positive relationships were found when student- and teacher-led activities were combined, which is referred to as guided inquiry (Aditomo \& Klieme, 2020; Jiang \& Mccomas, 2015) or interactive model or application (Areepattamannil, 2012; Lau \& Lam, 2017). While these findings seem to be consistent with results from 
experimental research in science education that showed teacher-guided inquiry had stronger effects than student-led investigations (e.g., Furtak et al., 2012), recent studies using ILSA data further demonstrated that the relationship between student-led investigations and science achievement followed a curvilinear pattern (Teig et al., 2018), including activities related to doing practical experiments in the laboratory (Cairns, 2019; Oliver et al., 2019) and drawing conclusions from the experiments (Oliver et al., 2019). Other teaching factors especially teacher support (Jerrim et al., 2019) and disciplinary climate (Chi et al., 2018), also seemed to play a significant role in moderating inquiry-achievement relationships.

While the majority of the studies examined the relationships between inquiry as an instructional approach and outcome in general population, only few studies further examined whether these relationships varied across sub-groups of students who shared similar characteristics, including gender, ethnicity, immigration background, socio-economic status (SES), and achievement level. The findings showed that inquiry activities were associated with low achievement of girls in Chinese regions (Chi et al., 2018) as well as girls in the United States, particularly for teacherled activities (Tang et al., 2018); however, no gender differences were found in the achievement of British students (Jerrim et al., 2019). While the combination of student-and teacher-led activities were significantly related to the Hispanic students' achievement in the United States, no significant differences existed between Caucasian, African American, and Hispanic students with respect to student-led investigations (Gao \& Wang, 2016). Teacher-led activities that focused on models or applications (e.g., teacher used examples to explain the relevance of science) had positive relationships with both native and immigrant students in Canada, whereas student-led investigations were negatively related to the achievement of only the native students (Areepattamannil \& Kaur, 2013). In the United States, low SES students-who had lower achievement compared to high SES students-were more likely to report the use of inquiry activities in their school science (Tang et al., 2018). In Chinese regions, these activities were negatively correlated with the achievement of low SES students, especially for girls (Chi et al., 2018), but such differential effects were practically non-existent across students with various levels of SES in England (Jerrim et al., 2019). Forbes et al. (2020) also found that high achieving students across 13 participating countries in PISA 2015 often engaged in teacher-led activities whereas those with the lowest achievement level frequently participated in students-led investigations. However, using similar data, Jerrim et al. (2019) demonstrated that the effects of inquiry on science achievement did not vary across students with different achievement levels in England. By utilizing TIMSS or PISA data, studies in this category can compare the extent to which different types of inquiry activities may benefit various sub-groups of students across countries. This research direction is particularly relevant for advancing research in science education as schools around the globe become increasingly more diverse (OECD, 2016b).

\section{Discussion}

The main goal of this study was to synthesize the knowledge gained from studies that utilized TIMSS and PISA data for investigating inquiry in science education. This study reviews the main aspects of TIMSS and PISA related studies by drawing upon the three strands of inquiry research: (1) inquiry as an instructional approach, (2) inquiry as an instructional outcome, and 
(3) inquiry as an instructional approach and outcome. It also discusses several opportunities and challenges for bridging research gaps in inquiry research by harnessing TIMSS and PISA data as well as recommendations for improving the assessment of inquiry in ILSAs.

In the first strand of inquiry research, almost all studies focused on identifying classroom/ teacher characteristics that explained the frequent implementation of inquiry as an instructional approach. Although TIMSS and PISA provide other information about student, school, and/or country characteristics as well as allow the comparison of findings across grades, countries, and cycles, very few studies in this category took advantage of these opportunities. Examples include a comparison of teachers' emphasis on inquiry investigation between classrooms in Finland and South Korea (Kang \& Keinonen, 2016) as well as between Grades 4, 5, 8, and 9 in Norway (Teig et al., 2019). As shown in Figure S1, ILSA data from developed countries were more frequently examined compared to developing countries. Figure 5 also showed that few researchers investigated this strand of inquiry research, and those who did prioritized their research focus on analyzing inquiry in secondary schools (i.e., TIMSS Grade 8 and PISA) rather than primary schools (i.e., TIMSS Grade 4).

Previous research has demonstrated that science teachers encounter considerable challenges in implementing inquiry in their classrooms (e.g., Chichekian \& Shore, 2016; Crawford, 2014). These challenges may be particularly strong for primary school teachers who teach in classrooms with insufficient teaching and learning resources. TIMSS data provide rich information that could contribute to understanding various challenges teachers encounter in implementing inquiry, especially by analyzing relevant variables at the student, teacher, school, or country level. The analyses may focus on understanding how these challenges differ between primary and secondary science classrooms within or between countries and whether these challenges remain across the assessment cycles. In addition to TIMSS, PISA also provides data from students, teachers, and principals that can be used to further explore the opportunities and challenges for the implementation of inquiry. These data can be linked with the Teaching and Learning International Survey (TALIS), which asked teachers and school leaders about teaching and learning environments at their schools. Starting in 2018, TALIS also added a video study that provides additional analytical insights into science teaching practice from the perspective of classroom observations. Future research could focus on utilizing these data to provide evidence in understanding effective implementation of inquiry as an instructional approach.

In the second strand of inquiry research, which focused on examining inquiry as an instructional outcome, most studies found the effects of item characteristics - such as cognitive demand, item format, and item dimension - on different aspects of students' science performance, including scientific inquiry. However, these studies only explored the assessment data from paper-based tests (e.g., Liou \& Bulut, 2017; Ruiz-Primo \& Li, 2016). As a result of recent advancement in technology, the assessment of student performance has shifted away from paper-and-pencil to computer-based platforms. This shift contributes to making the assessment of complex inquiry skills — such as testing and carrying out investigations, interpreting data, and drawing inferences-more visible (e.g., Teig, 2019). PISA piloted computer-based assessment of science in 2006 for three pioneering countries (Denmark, 
Iceland, and South Korea) and then implemented it worldwide in 2015 (OECD, 2016b). Most notably, PISA 2015 recorded student process data by constructing machine-generated log files that contain the records of all the steps and actions students took during the assessment, along with their corresponding timestamps. In 2019, TIMSS also transitioned to digital assessments, or eTIMSS, that allowed students to interact with digital environments and apply a wide range science knowledge (Mullis \& Martin, 2017). eTIMSS 2019 presented different types of problem-solving process and inquiry tasks referred to as PSIs. As in PISA 2015, eTIMSS also recorded student process data during the assessment as computer log files. Instead of merely providing information on whether students' responses were correct or incorrect (product data), log files offer additional insights into how the responses were produced or process data (Teig, Scherer, \& Kjærnsli, 2020). The vast amount of information stored in these log-file data could open new research avenues for understanding how students interact with computer-based inquiry tasks and shine a light on why some students are more successful at solving inquiry tasks than others (Teig, 2019). Although the digital shift toward computer-based platforms in PISA 2006 and 2015 has provided promising opportunities to investigate inquiry as an instructional outcome, none of the studies identified in this review took advantage of these data.

A growing body of research in science education has explored observable, behavioral indicators derived from process data to gain a better understanding of student performance in scientific inquiry. Process data from ILSAs could contribute to this recent research venue as they offer the potential of generalizability across populations within a country, while at the same time provide an opportunity for cross-country validation studies (Teig et al., 2020). By analyzing student process data, such as from eTIMSS 2019, researchers can identify different types of problem solving and inquiry strategies that underlie successful and unsuccessful performance across subjects, grades, or countries. Better yet, these data could also be integrated with other data sources (e.g., student or teacher questionnaires) to link student strategies in solving inquiry tasks during the assessment with instructional practices they experience in the classrooms in order to provide teachers with relevant suggestions for improving their instruction. Understanding the characteristics of student performance beyond their correct/incorrect responses would help teachers, researchers, and policy makers to gain insights into why some students are more successful at solving complex tasks than others and how to support teachers in improving students' scientific inquiry skills.

In the third strand of inquiry research, the majority of TIMSS and PISA related studies focused on investigating the relationships between inquiry as an instructional approach and outcome. Even though these studies used similar data, the conceptualization and measurement of inquiry varied considerably. This variation reflects the mainstream research in science education that differentiates inquiry based on the range and type of activities (Rönnebeck et al., 2016) and teacher guidance (Furtak et al., 2012; Vorholzer \& von Aufschnaiter, 2019). A great number of studies treated students' or teachers' responses on diverse inquiry activities as a single scale that consists of varying activities by using the existing index provided from the TIMSS or PISA database. However, recent evidence has revealed the risk of relying on such measures of inquiry, particularly for the inquiry scale from PISA 2015 or IBTEACH (Aditomo \& Klieme, 2020; Forbes et al., 2020; Oliver et al., 2019). The pattern of inquiry activities has been shown 
to vary substantially across regions (Aditomo \& Klieme, 2020; Forbes et al., 2020) and the levels of students' achievement (Forbes et al., 2020). Instead of forming a single universal pattern of inquiry-based instruction as presented in PISA 2015, the pattern seems to vary depending on the role of teacher guidance that separates teacher- and student-led activities (Aditomo \& Klieme, 2020). Hence, conducting measurement invariance testing to ensure the comparability of inquiry scales is highly recommended, especially for future research that utilizes the scale in a cross-country comparison study.

Although recent research has investigated the risk of employing the single inquiry scale from PISA, no study found in this review demonstrated a similar endeavor in examining the scale of Teacher Emphasize Science Investigation in TIMSS. This scale consists of not only independent inquiry investigation similar to PISA (e.g., students are asked to design or plan investigations), but also other activities including asking students to relate what they are learning in science to their daily lives or giving explanations about something they are studying (TIMSS 2011) and asking students to observe natural phenomena or doing field work outside the class (TIMSS 2015). Unlike the PISA inquiry scale that integrates student- and teacher-led activities, the TIMSS scale is derived from only student-led activities. More research is needed to examine whether the TIMSS scale in fact exhibits a single universal pattern, as presented in TIMSS international reports (e.g., Martin \& Mullis, 2013) and is invariant across countries when only student-led activities are used to form the scale.

Findings from this review also showed that there was no significant difference between assessing the frequent implementation of inquiry using student and teacher questionnaires. Both perspectives seem to be crucial for improving the assessment of inquiry as an instructional approach. While teachers' responses may be more susceptible to bias compared to students' responses, teachers were able to identify challenging instructional practices-like inquiry activities - better than their students (e.g., Kunter \& Baumert, 2006). As shown in Figure 5, most studies used PISA to assess inquiry as an instructional approach. Even though PISA assessed students' perceptions about a broader range of inquiry activities than TIMSS, these perceptions were framed at the school instead of classroom level and thus, suffer from methodological challenges associated with the investigation of teaching effectiveness as classroom-level processes (Teig et al., 2018). Furthermore, it is worth noting that the last TIMSS cycle in 2019 used both student and teacher questionnaires to measure inquiry as an instructional approach. Future studies could investigate whether students' responses, which reflect shared perception of inquiry at the classroom level, align with their teachers' responses across fourth and eighth grade science classrooms. Adding a more qualitative perspectivesuch as through classroom observations and interviews-would also be valuable in understanding how students and teachers perceive and assess different types and ranges of inquiry activities.

Almost all TIMSS and PISA related studies in this review encounter a similar drawback in relation to the cross-sectional design of ILSAs which prevents causal inferences. For instance, a reverse causality might exist when a correlational study exhibits a positive relationship between inquiry teaching and science achievement. On the one hand, these results could be interpreted as the frequent implementation of inquiry causing the increase in student 
achievement. On the other hand, teachers may simply implement inquiry activities more often for high- rather than low-achieving students. Jiang and Mccomas (2015) attempted to circumvent the causality issue by applying propensity score analysis to examine the effects of different levels of inquiry teaching on student achievement using PISA 2006. This study showed that providing students with a high level of independence during inquiry activities was not always beneficial, as the highest achievement were found when students were involved in guided instead of independent inquiry, particularly in conducting investigations and drawing conclusions from data (Jiang \& Mccomas, 2015). Furthermore, compared to previous studies that relied heavily on the cross-sectional data from TIMSS or PISA, Jerrim et al. (2019) took this research further by linking PISA 2015 data with the National Pupil Database in England. Using a longitudinal design, this study took into account students' prior as well as their later achievement in the national examination (Jerrim et al., 2019). They found a small positive effect of inquiry teaching on student achievement, after controlling for student demographics, prior achievement scores, and science courses (Jerrim et al., 2019). This effect was generally smaller compared to the previous meta-analyses on inquiry effectiveness in science education (e.g., Estrella et al., 2018; Furtak et al., 2012). Nevertheless, it should be emphasized that TIMSS and PISA studies assess how often inquiry as an instructional approach is implemented in "regular" classrooms or schools, whereas meta-analyses were based on experimental or quasi experimental studies that facilitated teachers with necessary training and assistance to implement innovative inquiry programs in a particular learning environment (Aditomo \& Klieme, 2020). Teachers in "average" schools, such as those schools who were selected to participate in ILSAs, were unlikely to receive such extensive supports for implementing inquiry in their classrooms (Aditomo \& Klieme, 2020). Thus, this study calls for further research to make causal inferences and identify causal pathway between the implementation of inquiry and student achievement. Such research could focus on investigating the effects of different types and ranges of inquiry activities across science classrooms in primary and secondary schools.

How should TIMSS and PISA studies improve the assessment of inquiry as an instructional approach and outcome? Since the conceptualization and measurement of inquiry vary according to the type and range of activities students are involved in as well as the extent of teacher guidance (e.g., Furtak et al., 2012; Rönnebeck et al., 2016; Vorholzer \& von Aufschnaiter, 2019), the assessment of this construct in TIMSS and PISA studies should also reflect these dimensions. While TIMSS mostly emphasizes activities related to independent investigations, PISA includes a more diverse range of activities related to not only experimentation but also critique and argumentation. In assessing inquiry as an instructional approach, both studies could benefit from adding relevant items that represent various types and ranges of inquiry activities in the classrooms, as commonly found in science education research as well as actual science classrooms (see Figure 1 for further details). Examples may include asking students and/or teachers about how often students are given opportunities to engage in the following activities:

- Ask questions about natural phenomena (Identifying research questions),

- Use multiple sources of evidence to explain natural phenomena (Developing explanations and Engaging in argumentation and reasoning), 
- Create scientific representations such as models, drawings, tables, charts, graphs, etc. (Constructing models, Developing explanations, and Communicating), or

- Use scientific terms/concepts to communicate understanding of natural phenomena (Understanding scientific concepts, Developing explanations, and Communicating).

While incorporating new types and ranges of inquiry activities into the existing assessment of inquiry as an instructional approach seems feasible, it remains challenging to reflect the measure of teacher guidance across these activities. Teacher guidance is a manifold contract, and its enactment in inquiry activities varies depending on (a) the degree of autonomy students have for individual decisions in each activity, (b) the degree of conceptual information students receive to support them in performing a particular inquiry activity, and (c) the cognitive domain targeted by the guidance, such as to address procedural and content-specific goals (Vorholzer \& von Aufschnaiter, 2019). For example, PISA 2015 asked students and/or teachers on how frequently "students are allowed to design their own experiments," whereas TIMSS 2019 asked teachers about how often their students "design experiments or investigations. Although students' responsibility and independence for planning the investigation is evident (i.e., the degree of autonomy), it is still unclear whether this activity can be entirely referred to as unguided or independent inquiry. Teachers might emphasize other guidance dimensions, such as by explaining and providing explicit examples on designing science experiments (i.e., the degree of conceptual information). Therefore, science education researchers interested in harnessing ILSAs to investigate inquiry should understand that the items used to measure inquiry as an instructional approach might be considered a crude diagnostic of teachers' implementation of inquiry. These items do not explicitly address teacher guidance and may not reflect real classroom applications. Due to the manifold nature of teacher guidance, further work is needed to construct an assessment of inquiry as an instructional approach that specifically reflects its various dimensions.

As TIMSS and PISA studies have transitioned to computer-based assessments, there is the potential to improve the assessment of inquiry as an instructional outcome by leveraging students' process data. The machine generated log files that record students' behaviors during the assessment provide a wealth of information about their strategies, actions, and decisionmaking processes in solving inquiry tasks. By integrating log-file data with students' final responses, the assessment scores could facilitate a broad description of students' inquiry performance. Rather than solely relying on students' final responses, the integration of process data into the overarching framework of science assessment in TIMSS and PISA may lead to more comprehensive, reliable, and valid inferences of student inquiry competence. In doing so, further work is needed to develop an assessment of inquiry that can properly capture students' interactions with inquiry tasks, such as their patterns of actions, sequences, and strategic behaviors, as observable evidence for the inquiry process. More specifically, establishing robust theoretical and empirical evidence is crucial for justifying the link between observable indicators in log-file data (e.g., sequence of student actions) and a specific cognitive latent process involved in inquiry practice. 


\section{F. Conclusion/Summary}

This chapter intended to provide a synthesis of how studies that leveraged TIMSS and PISA data to investigate inquiry in science education has evolved over the years. More specifically, it systematically reviewed the patterns and findings from these studies by drawing upon the three main strands of inquiry research: (1) inquiry as an instructional approach, (2) inquiry as an instructional outcome, and (3) inquiry as an instructional approach and outcome. The findings indicated that most studies concentrated on the third strand of inquiry research to examine the relationship between inquiry and science achievement. This study calls for further research in other areas of inquiry and highlights a number of opportunities that may contribute to closing gaps in inquiry research by harnessing TIMSS and PISA data. It also discusses some recommendations for improving the assessment of inquiry as an instructional approach and outcome in TIMSS and PISA.

\section{G. Cross-References}

\subsubsection{Sampling design in ILSA}

3.1.5 ILSA questionnaires: Development, reporting, analyses, and future considerations

\section{H. Disclosure statement}

A condensed version of this chapter based on an outdated review process from 2019 has been published as Teig, N. (2019). Scientific inquiry in TIMSS and PISA 2015: Inquiry as an instructional approach and the assessment of inquiry as an instructional outcome in science. (Doctoral dissertation). University of Oslo, Norway.

\section{References}

Abd-El-Khalick, F., Boujaoude, S., Duschl, R. A., Lederman, N. G., Mamlok-Naaman, R., Hofstein, A., . . . Tuan, H. 1. (2004). Inquiry in science education: International perspectives. Science Education, 88(3), 397-419.

Aditomo, A., \& Klieme, E. (2020). Forms of inquiry-based science instruction and their relations with learning outcomes: evidence from high and low-performing education systems. International Journal of Science Education, 42(4), 504-525.

Areepattamannil, S. (2012). Effects of inquiry-based science instruction on science achievement and interest in science: Evidence from qatar. The Journal of Educational Research, 105(2), 134-146.

Areepattamannil, S., \& Kaur, B. (2013). Factors predicting science achievement of immigrant and non-immigrant students: A multilevel analysis. International Journal of Science Mathematics Education, 11(5), 1183-1207.

Cairns, D. (2019). Investigating the relationship between instructional practices and science achievement in an inquiry-based learning environment. International Journal of Science Education, 41(15), 2113-2135. doi:10.1080/09500693.2019.1660927

Cairns, D., \& Areepattamannil, S. (2017). Exploring the relations of inquiry-based teaching to science achievement and dispositions in 54 countries. Research in Science Education, 49(1), 1-23.

Chi, S., Liu, X., Wang, Z., \& Won Han, S. (2018). Moderation of the effects of scientific inquiry activities on low ses students' PISA 2015 science achievement by school teacher 
support and disciplinary climate in science classroom across gender. International Journal of Science Education, 40(11), 1284-1304.

Chichekian, T., \& Shore, B. M. (2016). Preservice and practicing teachers' self-efficacy for inquiry-based instruction. Cogent Education, 3(1), 1236872.

Collier, T., Morell, L., \& Wilson, M. (2018). Exploring the item features of a science assessment with complex tasks. Measurement, 114, 16-24.

Crawford, B. A. (2014). From inquiry to scientific practices in the science classroom. In N. G. Lederman \& S. K. Abell (Eds.), Handbook of research on science education (pp. 529556). New York: Routledge.

Estrella, G., Au, J., Jaeggi, S. M., \& Collins, P. (2018). Is inquiry science instruction effective for English language learners? A meta-analytic review. AERA Open, 4(2), 1-23.

Forbes, C. T., Neumann, K., \& Schiepe-Tiska, A. (2020). Patterns of inquiry-based science instruction and student science achievement in PISA 2015. International Journal of Science Education, 1-24. doi:10.1080/09500693.2020.1730017

Furtak, E. M., \& Penuel, W. R. (2019). Coming to terms: Addressing the persistence of "handson" and other reform terminology in the era of science as practice. Science education, 103(1), 167-186. Retrieved from https://doi.org/10.1002/sce.21488

Furtak, E. M., Seidel, T., Iverson, H., \& Briggs, D. C. (2012). Experimental and quasiexperimental studies of inquiry-based science teaching. Review of Educational Research, 82(3), 300-329.

Gao, S. (2014). Relationship between science teaching practices and students' achievement in singapore, chinese taipei, and the us: An analysis using TIMSS 2011 data. Frontiers of Education in China, 9(4), 519-551.

Gao, S., \& Wang, J. (2016). Do variations of science teaching approaches make difference in shaping student content and problem solving achievement across different racial/ethnic groups? International Journal of Environmental and Science Education, 11(12), 54045428.

Gough, D., Oliver, S., \& Thomas, J. (2017). An introduction to systematic reviews. Thousand Oaks, California: Sage.

Hopfenbeck, T. N., Lenkeit, J., El Masri, Y., Cantrell, K., Ryan, J., \& Baird, J.-A. (2018). Lessons learned from PISA: A systematic review of peer-reviewed articles on the programme for international student assessment. Scandinavian Journal of Educational Research, 62(3), 333-353.

Jerrim, J., Oliver, M., \& Sims, S. (2019). The relationship between inquiry-based teaching and students' achievement. New evidence from a longitudinal PISA study in england. Learning and Instruction, 61, 35-44.

Jiang, F., \& Mccomas, W. F. (2015). The effects of inquiry teaching on student science achievement and attitudes: Evidence from propensity score analysis of pisa data. International Journal of Science Education, 37(3), 554-576. doi:10.1080/09500693.2014.1000426

Kabiri, M., Ghazi-Tabatabaei, M., Bazargan, A., Shokoohi-Yekta, M., \& Kharrazi, K. (2017). Diagnosing competency mastery in science: An application of GDM to TIMSS 2011 data. Applied Measurement in Education, 30(1), 27-38.

Kang, J., \& Keinonen, T. (2016). Examining factors affecting implementation of inquiry-based learning in Finland and South Korea. Problems of Education in the 21 st Century, 74.

Kaya, S., \& Rice, D. C. (2010). Multilevel effects of student and classroom factors on elementary science achievement in five countries. International Journal of Science Education, 32(10), 1337-1363.

Klieme, E., Pauli, C., \& Reusser, K. (2009). The pythagoras study: Investigating effects of teaching and learning in swiss and german mathematics classrooms. In T. Janik \& T. 
Seidel (Eds.), The power of video studies in investigating teaching and learning in the classroom (pp. 137-160). Münster, Germany: Waxmann.

Kunter, M., \& Baumert, J. (2006). Who is the expert? Construct and criteria validity of student and teacher ratings of instruction. Learning Environments Research, 9(3), 231-251.

Lau, K.-c., \& Lam, T. Y.-p. (2017). Instructional practices and science performance of 10 topperforming regions in PISA 2015. International Journal of Science Education, 39(15), 2128-2149.

Lavonen, J., \& Laaksonen, S. (2009). Context of teaching and learning school science in Finland: Reflections on PISA 2006 results. Journal of Research in Science Teaching, 46(8), 922-944. Retrieved from https://doi.org/10.1002/tea.20339

Liou, P.-Y., \& Bulut, O. (2017). The effects of item format and cognitive domain on students' science performance in TIMSS 2011. Research in Science Education.

Liou, P.-Y., \& Hung, Y.-C. (2015). Statistical techniques utilized in analyzing PISA and TIMSS data in science education from 1996 to 2013: A methodological review. International Journal of Science and Mathematics Education, 13(6), 1449-1468.

Martin, M. O., \& Mullis, I. V. (2013). TIMSS 2015 assessment frameworks. Chestnut Hill, MA: TIMSS \& PIRLS International Study Center, Boston College and International Association for the Evaluation of Educational Achievement (IEA).

Mullis, I. V., \& Martin, M. O. (2017). TIMSS 2019 Assessment Frameworks. Boston College: TIMSS \& PIRLS International Study Center.

Mullis, I. V., Martin, M. O., Ruddock, G. J., O'Sullivan, C. Y., \& Preuschoff, C. (2009). TIMSS 2011 Assessment Framework. Retrieved from Boston College, TIMSS \& PIRLS International Study Center: http://timssandpirls.bc.edu/timss2015/international-results/

National Research Council. (1996). National science education standards. Washington, DC: National Academies Press.

National Research Council. (2012). A framework for K-12 science education: Practices, crosscutting concepts, and core ideas. Washington, DC: National Academies Press.

National Research Council. (2013). Next generation science standards: For states, by states. Washington, DC: The National Academies Press.

OECD. (2006). Assessing scientific, reading and mathematical literacy : A framework for PISA 2006. Paris: OECD Publishing.

OECD. (2016a). PISA 2015 assessment and analytical framework: Science, reading, mathematic and financial literacy. Paris: OECD Publishing.

OECD. (2016b). PISA 2015 results (volume II) policies and practices for successful schools. Paris: OECD Publishing.

Oliver, M., McConney, A., \& Woods-McConney, A. (2019). The Efficacy of Inquiry-Based Instruction in Science: a Comparative Analysis of Six Countries Using PISA 2015. Research in Science Education. doi:10.1007/s11165-019-09901-0

Pongsophon, P., \& Herman, B. C. (2017). A theory of planned behaviour-based analysis of TIMSS 2011 to determine factors influencing inquiry teaching practices in highperforming countries. International Journal of Science Education, 39(10), 1304-1325.

Rocard, M., Csermely, P., Jorde, D., Dieter Lenzen, Walberg-Henriksson, H., \& Hemmo, V. (2007). Science education now: A renewed pedagogy for the future of europe. Retrieved from https://ec.europa.eu/research/science-society/document_library/pdf_06/reportrocard-on-science-education en.pdf

Rönnebeck, S., Bernholt, S., \& Ropohl, M. (2016). Searching for a common ground-a literature review of empirical research on scientific inquiry activities. Studies in Science Education, 52(2), 161-197. 
Ruiz-Primo, M.-A., \& Li, M. (2016). PISA science contextualized items: The link between the cognitive demands and context characteristics of the items. e-Journal of Educational Research, Assessment and Evaluation, 22(1).

Scheerens, J. (1990). School effectiveness research and the development of process indicators of school functioning. School Effectiveness and School Improvement, 1(1), 61-80.

Tang, N.-E., Tsai, C.-L., Barrow, L., \& Romine, W. (2018). Impacts of enquiry-based science teaching on achievement gap between high-and-low SES students: findings from PISA 2015. International Journal of Science Education, 41(4), 448-470.

Teig, N. (2019). Scientific inquiry in TIMSS and PISA 2015: Inquiry as an instructional approach and the assessment of inquiry as an instructional outcome in science. ( $\mathrm{PhD}$ Dissertation). University of Oslo, Norway. Retrieved from https://www.duo.uio.no/handle/10852/71649

Teig, N., Scherer, R., \& Kjærnsli, M. (2020). Identifying patterns of students' performance on simulated inquiry tasks using PISA 2015 log-file data. Journal of research in science teaching. doi:10.1002/tea.21657

Teig, N., Scherer, R., \& Nilsen, T. (2018). More isn't always better: The curvilinear relationship between inquiry-based teaching and student achievement in science. Learning and Instruction, 56, 20-29. doi:10.1016/j.learninstruc.2018.02.006

Teig, N., Scherer, R., \& Nilsen, T. (2019). I know I can, but do I have the time? The role of teachers' self-efficacy and perceived time constraints in implementing cognitiveactivation strategies in science. Front Psychol, 10(July), 1697. doi:10.3389/fpsyg.2019.01697

Vorholzer, A., \& von Aufschnaiter, C. (2019). Guidance in inquiry-based instruction - an attempt to disentangle a manifold construct. International Journal of Science Education, 41(11), 1562-1577.

Yip, D. Y., Chiu, M. M., \& Ho, E. S. C. (2004). Hong Kong student achievement in OECDPISA study: Gender differences in science content, literacy skills, and test item formats. International Journal of Science Mathematics Education, 2(1), 91-106. 